\title{
Dupilumab reduces systemic corticosteroid use and sinonasal surgery rate in CRSwNP*
}

\author{
Martin Desrosiers', Leda P. Mannent ${ }^{2}$, Nikhil Amin ${ }^{3}$, G. Walter Canonica4, \\ Peter W. Hellings ${ }^{5}$, Philippe Gevaert ${ }^{6}$, Joaquim Mullol', Stella E. Lee ${ }^{8}$, \\ Shigeharu Fujieda ${ }^{9}$, Joseph K. Han ${ }^{10}$, Claire Hopkins ${ }^{11}$, Wytske Fokkens ${ }^{12}$, \\ Roger Jankowski ${ }^{13}$, Seong H. Cho ${ }^{14}$, Xuezhou Mao ${ }^{15}$, Mei Zhang ${ }^{15}$, \\ Megan S. Rice ${ }^{16}$, Asif H. Khan², Siddhesh Kamat ${ }^{3}$, Naimish Patel ${ }^{15}$, \\ Neil M.H. Graham*, Marcella Ruddy ${ }^{3}$, Claus Bachert ${ }^{6,17,18}$

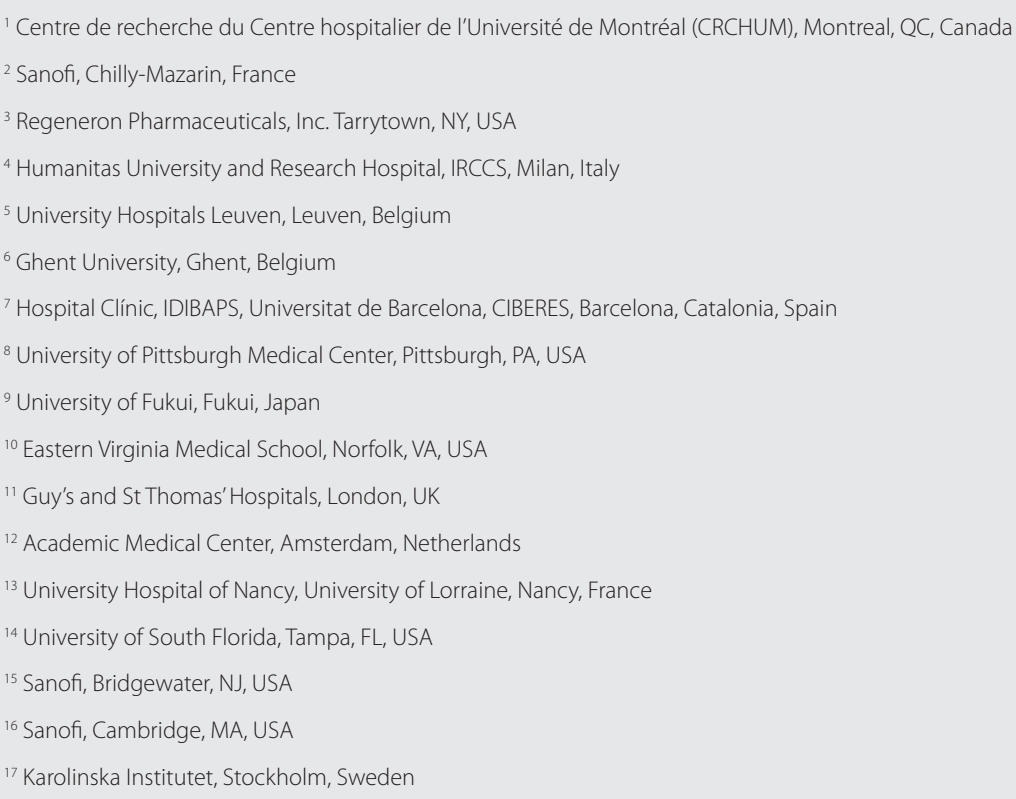

Rhinology 59: 3, 301 - 311, 2021

https://doi.org/10.4193/Rhin20.415

*Received for publication:

August 20, 2020

Accepted: January 19, 2021

\section{Abstract}

Background: Chronic rhinosinusitis with nasal polyps (CRSWNP) is a type 2 inflammatory disease with a high symptom burden and poor quality of life. Treatment options include recurrent surgeries and/or frequent systemic corticosteroids (SCS). Dupilumab, a fully human monoclonal antibody, blocks the shared receptor component for interleukin-4 and interleukin-13, key drivers of type 2-mediated inflammation. We report results of pooled analyses from 2 randomised, double-blind, placebo-controlled phase 3 studies (SINUS 24 [NCT02912468]; SINUS-52 [NCT02898454]) to evaluate dupilumab effect versus placebo in adults with CRSwNP with/without SCS use and sinonasal surgery.

Methodology: SINUS-24 patients were randomised 1:1 to subcutaneous dupilumab $300 \mathrm{mg}(\mathrm{n}=143)$ or placebo ( $\mathrm{n}=133)$ every 2 weeks (q2w) for 24 weeks. SINUS-52 patients were randomised 1:1:1 to 52 weeks of subcutaneous dupilumab $300 \mathrm{mg}$ q2 $w$ $(n=150), 24$ weeks q2w followed by 28 weeks of dupilumab 300 mg every 4 weeks $(n=145)$ or 52 weeks of placebo q2w ( $n=153)$.

Results: Dupilumab reduced the number of patients undergoing sinonasal surgery (82.6\%), the need for in-study SCS use (73.9\%), and SCS courses (75.3\%). Significant improvements were observed with dupilumab vs placebo regardless of prior sinonasal sur- 
gery or SCS use in nasal polyp, nasal congestion, Lund-MacKay, and Sinonasal Outcome Test (22-items) scores, and the University of Pennsylvania Smell Identification Test.

Conclusions: Dupilumab demonstrated significant improvements in disease signs and symptoms and reduced the need for sinonasal surgery and SCS use versus placebo in patients with severe CRSWNP, regardless of SCS use in the previous 2 years, or prior sinonasal surgery.

Key words: nasal polyps, paranasal sinus diseases, rhinitis, sinusitis

\section{Introduction}

Chronic rhinosinusitis with nasal polyps (CRSwNP) is a chronic inflammatory disease of the nose and paranasal sinuses characterised by symptoms of rhinosinusitis for $\geq 3$ months, nasal polyps and sinus disease/involvement ${ }^{(1)}$. CRSwNP is associated with a high symptom burden and poor health-related quality of life $(\mathrm{HRQOL})^{(2)}$.

Treatment guidelines for CRSwNP recommend a stepwise approach based on disease severity that includes nasal saline irrigation and topical/local intranasal corticosteroids (INCS), and short courses of oral corticosteroids for uncontrolled severe disease ${ }^{(1,3)}$. Patients who are refractory to medical therapy may benefit from endoscopic sinus surgery (ESS), although postoperative nasal polyp recurrence is common, with reported recurrence rates of approximately $40 \%$ of patients within 18 months of ESS to nearly $80 \%$ within 12 years ${ }^{(4-6)}$. The rate of repeated surgeries is higher among patients with a more pronounced type 2 inflammatory signature, which can be identified by asthma and non-steroidal anti-inflammatory drug-exacerbated respiratory disease (N-ERD) comorbidities or increased eosinophil counts and higher interleukin (IL)-5 and immunoglobulin (Ig)E levels in nasal or sinus tissue ${ }^{(4,7,8)}$. Common adverse events (AEs) linked to prolonged systemic corticosteroid use have been well documented, along with their associated costs ${ }^{(9-12)}$, highlighting the need for corticosteroid-sparing therapies.

Dupilumab is a fully human Veloclmmune ${ }^{\circledR}$-derived monoclonal antibody ${ }^{(13,14)}$, that inhibits signalling of both IL-4 and IL-13, key and central cytokines involved in type 2-mediated inflammation $^{(15,16)}$. Dupilumab is the first biologic treatment approved by the US Food and Drug Administration, the European Medicines Agency and the Japanese Ministry of Health, Labour and Welfare as an add-on maintenance treatment in adult patients with inadequately controlled CRSwNP(17-19).

The phase 3 studies SINUS-24 (NCT02912468) and SINUS-52 (NCT02898454) investigated dupilumab added to a background of INCS (mometasone furoate nasal spray [MFNS]) in severe CRSwNP uncontrolled by standard of care ${ }^{(20)}$. Dupilumab significantly improved endoscopic (nasal polyp score [NPS]), radiographic (Lund MacKay-CT [LMK-CT] score), clinical (nasal congestion [NC], total symptom score and University of Pennsyl- vania Smell Identification Test [UPSIT] score) and HRQoL outcomes (22-item Sino-Nasal Outcome Test [SNOT-22]). Dupilumab also improved lung function and asthma control in the subset of patients with comorbid asthma.

These analyses examined a pooled population of patients with CRSwNP enrolled in the SINUS-24 and SINUS-52 studies. The objective was to investigate whether dupilumab was superior to standard of care in reducing the need for systemic corticosteroid (SCS) use or sinonasal surgery, both after SCS use in the study and in subgroups of patients with/without prior SCS use or sinonasal surgery.

\section{Materials and methods}

\section{Study design}

SINUS-24 and SINUS-52 were randomised, multicentre, doubleblind, placebo-controlled, parallel-group studies assessing dupilumab as an add-on treatment to standard of care in adults with severe CRSWNP(20). In SINUS-24, patients were randomly assigned (1:1) to subcutaneous dupilumab $300 \mathrm{mg}$ or placebo every 2 weeks (q2w) for 24 weeks; in SINUS-52, patients were randomised (1:1:1) to dupilumab $300 \mathrm{mg}$ q2 $\mathrm{w}$ for 52 weeks (Arm A), to dupilumab $300 \mathrm{mg}$ dosed $\mathrm{q} 2 \mathrm{w}$ for 24 weeks followed by every 4 weeks (q4w) for the remaining 28 weeks (Arm B) or to placebo q2w for 52 weeks (Arm C). During a 4-week run-in period, and throughout the trial, patients received $100 \mu \mathrm{g}$ MFNS in each nostril twice daily. Concomitant rescue treatment with short courses of SCSs, systemic antibiotics and sinonasal surgery was allowed at the investigator's discretion during the studies. At the time of surgery, patients were permanently discontinued from study treatment.

The studies were conducted in accordance with the Declaration of Helsinki, International Conference on Harmonization Good Clinical Practice guidelines and applicable regulatory requirements. An independent data and safety monitoring committee conducted blinded monitoring of patient safety data, and the local institutional review board or ethics committee at each study centre oversaw trial conduct and documentation. All patients provided written informed consent before participating in the trial. 


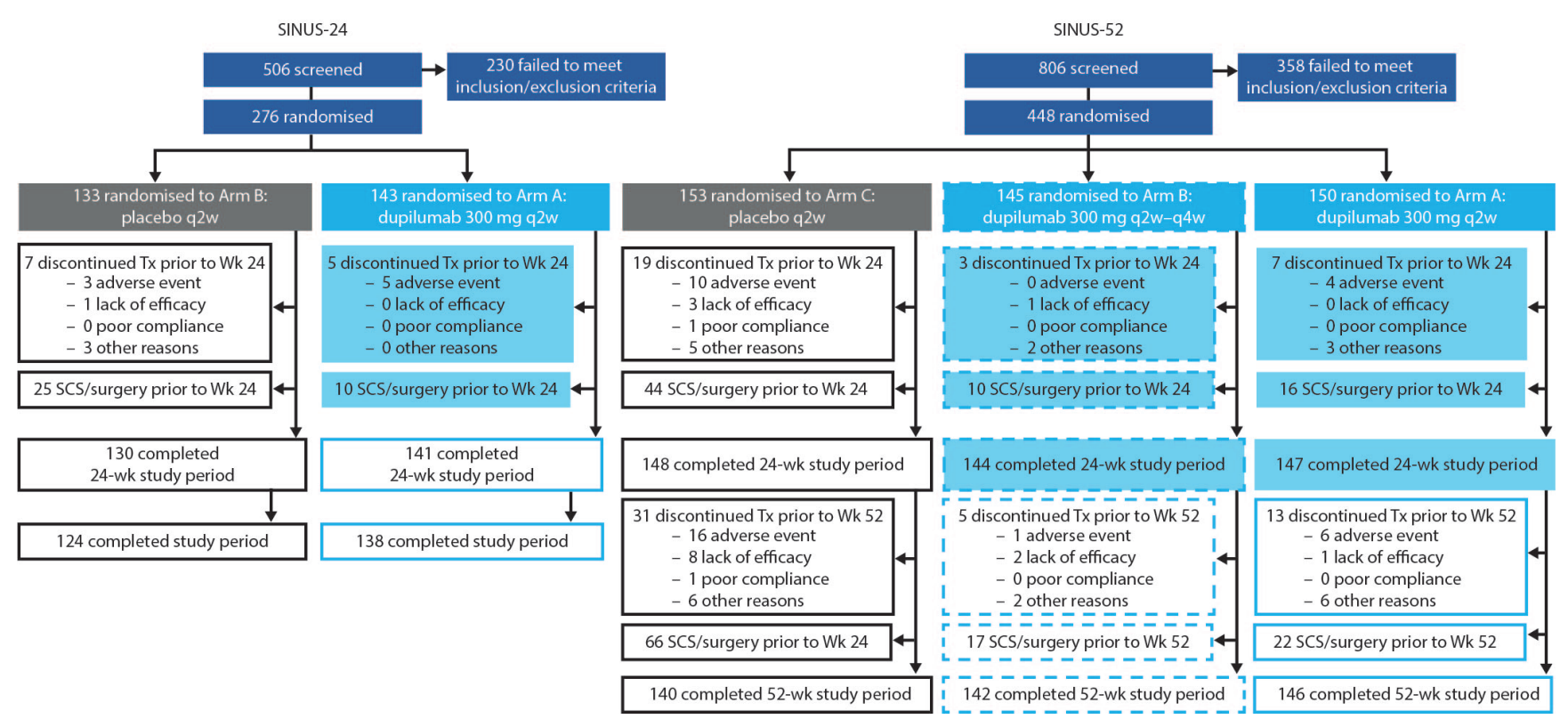

Figure 1. Patients enrolled and included in the analysis. q2w: every 2 weeks, q4w: every 4 weeks, SCS: systemic corticosteroid, Tx: treatment, Wk: Week.

Eligibility criteria and subgroups analysed

Adult patients with CRSwNP who had undergone prior treatment with SCSs (or for whom SCSs were contraindicated or not tolerated) in the past 2 years OR who had had prior surgery for nasal polyps (NP) were eligible for enrolment if they fulfilled the following criteria: had bilateral NP despite treatment with INCS for $\geq 2$ months and with a total NPS of $\geq 5$ (out of 8 ), and $\geq 2$ for each nostril; ongoing symptoms of $\mathrm{NC} /$ nasal blockade/nasal obstruction (for $\geq 8$ weeks before Visit 1 [V1]) with a symptom severity score of 2 or 3 (moderate or severe) at V1 and a weekly average severity score of $>1$ at randomisation (V2) AND $\geq 1$ other symptom such as reduction in/loss of smell or anterior rhinorrhoea/postnasal drip.

Patients were excluded if they had undergone monoclonal antibody and/or immunosuppressive treatment within 2 months, or anti-IgE therapy (omalizumab) within 130 days, of screening; had undergone sinus surgery (including polypectomy) within 6 months before screening or sinonasal surgery that structurally altered the lateral wall of the nose making the evaluation of NPS impossible; or if they had a forced expiratory volume in 1 second of $\leq 50 \%$ of the predicted normal value.

Patients were stratified at baseline according to the following: history of asthma, including aspirin-exacerbated respiratory disease (AERD)/N-ERD (yes/no); prior sinonasal surgery (yes/ no); and country. Type of previous sinonasal surgery was not specified.

\section{Outcome measures}

The effect of dupilumab on the need for SCS use or sinonasal surgery was assessed by measuring the proportion of patients requiring SCSs or who underwent or planned for sinonasal surgery during the study treatment period. The reason for SCS use, the annualised SCS dose (mg), and the duration (days) and number of SCS courses were also documented. Subgroup analyses to evaluate efficacy in patients with/without prior surgery and in patients with/without prior SCS use were also conducted. Sensitivity analyses, including data recorded after SCS use, were conducted on the primary endpoints, NPS and NC score and on the key secondary endpoint of LMK-CT score. Safety was measured by pooling safety data overall and in patients with/without SCS use or sinonasal surgery during treatment.

\section{Statistical analysis}

This pooled analysis combined all patients from the 2 studies randomised to the dupilumab $300 \mathrm{mg}$ q2w dosing - Arm A over the 52-week treatment period and Arm B (first 24 weeks q2w) of SINUS-52, and dupilumab arm of SINUS-24. For the placebo group, the placebo arms of both SINUS-24 up to Week 24 and SINUS-52 up to Week 52 were combined.

The Kaplan-Meier (K-M) method was used to estimate probabilities of events up to Week 52 with the hazard ratio (HR) derived from a Cox proportional hazard model with the event of first SCS use and/or NP surgery (patients who underwent or planned, whichever is earlier) as the response variable and treatment, asthma/AERD status, prior surgery history, region (pooled country) and study indicator (0 for SINUS-52 and 1 for SINUS-24) as covariates. The proportion and time-to-event of patients requiring rescue treatment (defined as SCS use or sinonasal surgery [actual or planned during the study]) during the treatment period for dupilumab $300 \mathrm{mg}$ q2w versus placebo were prespecified, multiplicity-adjusted efficacy endpoints. For primary and key secondary endpoints, data collected after 
Table 1. Baseline characteristics for patients with/without prior SCS use or with/without prior sinonasal surgery.

\begin{tabular}{|c|c|c|c|c|}
\hline Characteristic & $\begin{array}{l}\text { With prior } \\
\text { SCS use }\end{array}$ & $\begin{array}{l}\text { Without prior } \\
\text { SCS use }\end{array}$ & $\begin{array}{c}\text { With prior } \\
\text { sinonasal surgery }\end{array}$ & $\begin{array}{l}\text { Without prior } \\
\text { sinonasal surgery }\end{array}$ \\
\hline & $\begin{array}{l}\text { All patients } \\
(n=538)\end{array}$ & $\begin{array}{l}\text { All patients } \\
(n=186)\end{array}$ & $\begin{array}{l}\text { All patients } \\
(n=459)\end{array}$ & $\begin{array}{l}\text { All patients } \\
(n=265)\end{array}$ \\
\hline Age, mean (SD), y & $50.79(12.87)$ & $53.15(12.57)$ & $51.38(12.61)$ & $51.42(13.22)$ \\
\hline Male sex, n (\%) & $338(62.8)$ & $99(53.2)$ & $268(58.4)$ & $169(63.8)$ \\
\hline NP duration, mean (SD), y & $10.17(9.29)$ & $13.41(9.49)$ & $14.20(9.62)$ & $5.53(6.02)$ \\
\hline Bilateral endoscopic NPS, mean (SD), $0-8^{\dagger}$ & $6.01(1.26)$ & $5.85(1.22)$ & $5.86(1.26)$ & $6.15(1.20)$ \\
\hline Nasal congestion (AM) score, mean (SD), $0-3^{+}$ & $2.42(0.57)$ & $2.34(0.61)$ & $2.44(0.56)$ & $2.33(0.60)$ \\
\hline SNOT-22 total score, mean (SD), $0-110^{+}$ & $52.14(20.78)$ & $47.37(19.92)$ & $51.63(20.19)$ & $49.72(21.44)$ \\
\hline Smell test (UPSIT) score, mean (SD), $0-40^{+}$ & $14.08(7.94)$ & $13.67(8.99)$ & $12.80(7.52)$ & $16.02(8.93)$ \\
\hline Sense of smell loss (AM) score, mean (SD), $0-3^{+}$ & $2.76(0.48)$ & $2.68(0.65)$ & $2.79(0.52)$ & $2.65(0.54)$ \\
\hline LMK-CT score, mean (SD), 0-24 ${ }^{\dagger}$ & $18.28(4.06)$ & $18.63(4.06)$ & $19.07(3.97)$ & $17.15(3.92)$ \\
\hline TSS, mean (SD), $0-9^{+}$ & $7.21(1.41)$ & $6.99(1.46)$ & $7.29(1.35)$ & $6.92(1.52)$ \\
\hline Rhinosinusitis severity (VAS), mean (SD), $0-10 \mathrm{~cm} \mathrm{scale}{ }^{\dagger}$ & $7.92(2.09)$ & $7.75(2.02)$ & $8.00(2.00)$ & $7.68(2.18)$ \\
\hline Blood eosinophils, mean (SD), median, Giga/L & 0.44 (0.35), 0.36 & $0.42(0.33), 0.33$ & $0.47(0.36), 0.37$ & $0.37(0.31), 0.29$ \\
\hline Total IgE, mean (SD), median, IU/mL & $\begin{array}{c}242.46(332.85), \\
131.00\end{array}$ & $\begin{array}{c}190.53(267.73) \\
94.00\end{array}$ & $\begin{array}{c}222.31(323.75) \\
108.50\end{array}$ & $\begin{array}{c}241.22(308.35), \\
134.00\end{array}$ \\
\hline Patients with comorbid asthma, n (\%) & $324(60.2)$ & $104(55.9)$ & $304(66.2)$ & $124(46.8)$ \\
\hline Patients with comorbid NSAID-ERD, n (\%) & $148(27.5)$ & $56(30.1)$ & $159(34.6)$ & $45(17.0)$ \\
\hline Patients with $\geq 1$ prior sinonasal surgery, $\mathrm{n}(\%)$ & $292(54.3)$ & $167(89.8)$ & $459(100.0)$ & NA \\
\hline Previous sinonasal surgeries, mean (SD) & $1.97(1.55)$ & $1.93(1.59)$ & $1.96(1.56)$ & NA \\
\hline Time since most recent sinonasal surgery, mean (SD), y & $7.14(6.35)$ & $7.18(6.60)$ & $7.16(6.44)$ & NA \\
\hline Time since last course of SCS use $\mathrm{f}^{\neq, \S}$ mean (SD), $d$ & $216.75(186.45)$ & NA & $216.60(181.49)$ & $216.95(193.70)$ \\
\hline Patients with SCS use in the previous $2 \mathrm{y}, \mathrm{n}(\%)$ & $538(100)$ & NA & $292(63.6)$ & $246(92.8)$ \\
\hline Number of SCS courses in the previous $2 \mathrm{y}$, mean (SD) & $1.55(1.19)$ & NA & $1.69(1.40)$ & $1.39(0.85)$ \\
\hline
\end{tabular}

TSS is a composite severity score consisting of the sum of daily symptoms of NC, loss of smell, and anterior/posterior rhinorrhoea. MCID for SNOT-22 score is 8.9. ${ }^{\dagger}$ Higher mean scores indicate more severe disease, except for UPSIT score where lower mean scores indicate more severe disease. ${ }^{\ddagger}$ Data are based on the pooled population: all patients randomised to dupilumab $300 \mathrm{mg}$ either q2w or q2w-q4w. ${ }^{\S} \mathrm{Number}$ of patients with $\geq 1$ day of SCS use and complete end dates reported. AM: morning, CT: computed tomography, d: day, LMK: Lund-Mackay, MCID: minimum clinically important difference, NC: nasal congestion, NP: nasal polyps, NPS: nasal polyp score, NSAID-ERD: non-steroidal anti-inflammatory drug-exacerbated respiratory disease, q2w: every 2 weeks, q4w: every 4 weeks, SNOT-22: 22-item Sino-Nasal Outcomes Test, SCS: systemic corticosteroid, SD: standard deviation, TSS: total symptom score, UPSIT: University of Pennsylvania Smell Identification Test, VAS: visual analogue scale: $y, y e a r$.

treatment discontinuation were included. For the purpose of the primary analysis, data post-SCS use or sinonasal surgery were set to missing and imputed by worst observation carried forward (WOCF); missing data without SCS use or sinonasal surgery were imputed by multiple imputation (MI) methods. Each of the imputed complete data sets were analysed by fitting an ANCOVA model with the corresponding baseline value, treatment group, prior surgery history, asthma/NSAID-ERD comorbidity status and study regions as covariates.

A sensitivity analysis conducted as an 'as-observed analysis' included data collected after SCS use for any reason and treatment discontinuation but excluded post-NP surgery data.

\section{Results}

Study patients and baseline characteristics

A total of 276 patients were randomised into SINUS-24 and 448 patients were randomised into SINUS 52 (Figure 1).

Baseline characteristics for patients with/without prior SCS use and with/without prior sinonasal surgery are outlined in Table

1. Patient baseline characteristics stratified by treatment group are provided in Table E1 of the online repository. A total of 459 (63.4\%) patients had a history of prior sinonasal surgery with a mean of approximately 7 years since their most recent surgery. The mean number of prior surgeries among these patients was 1.96. A total of 538 (74.3\%) patients had required SCSs during the previous 2 years with a mean of around 217 days since 
A

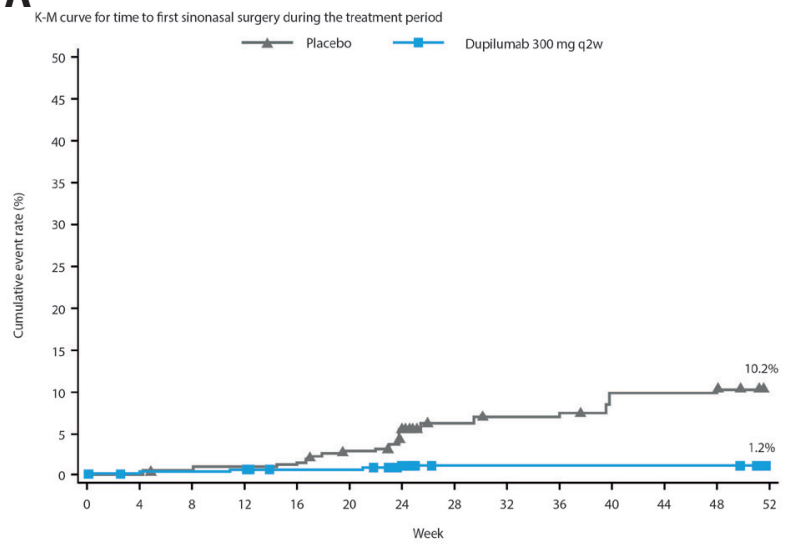

Patients with sinonasal surgery during the treatment period by disease characteristics subgroups

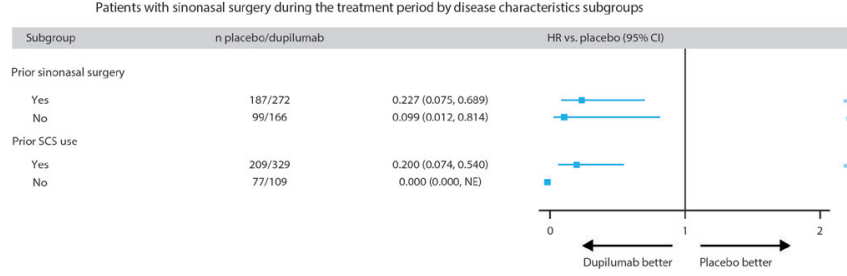

C

K-M curve for time to first SCS use during the treatment period

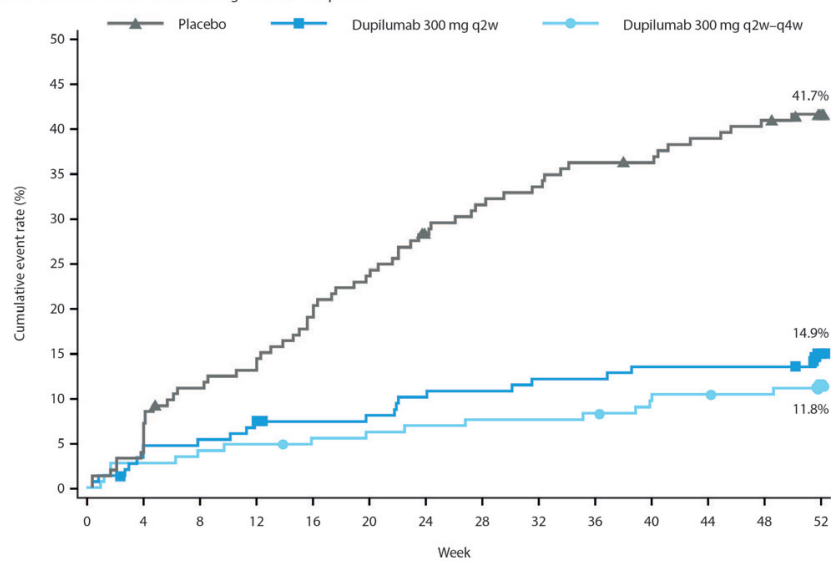

$\mathbf{B}_{\mathrm{k}-\mathrm{n}}$
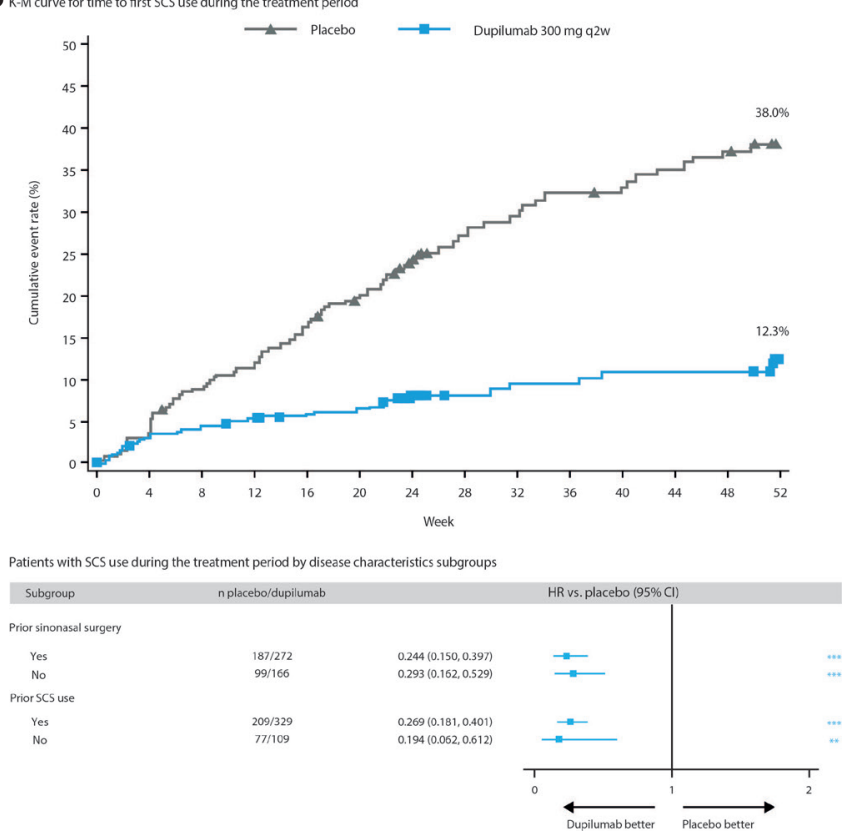

D

K-M curve for time to first SCS use during the treatment period

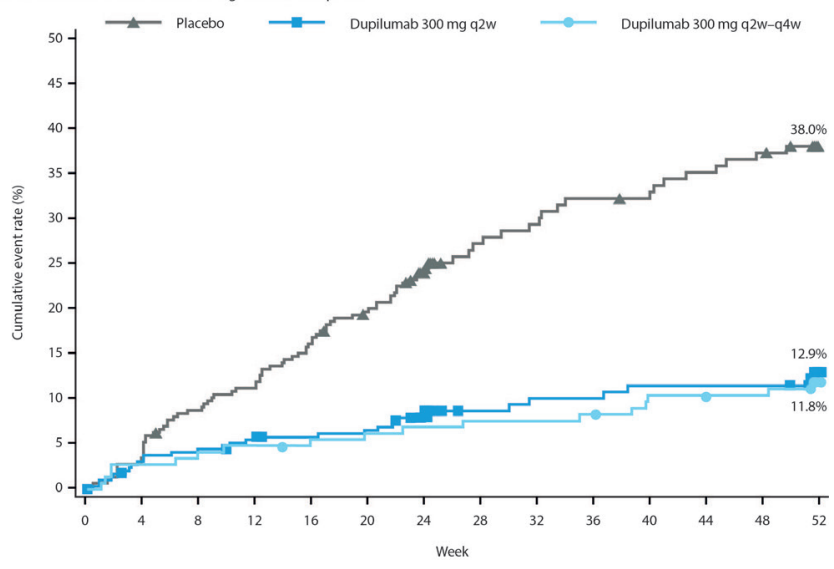

Figure 2. Need for (A) sinonasal surgery - pooled ITT and (B-D) SCS use during the treatment period: (B) dupilumab q2w- pooled ITT; (C) dupilumab q2w and q2w-q4w - SINUS-52 ITT; (D) dupilumab q2w and q2w-q4w - pooled ITT. ${ }^{*} p<0.05,{ }^{* *} p<0.01,{ }^{* * *} p<0.0001$. HR was derived from a Cox proportional hazard model with the event of first sinonasal surgery (planned or actual, whichever came first) or SCS use as the response variable and treatment, asthma/NSAID-ERD status, region (pooled country) and study indicator (EFC14280 $=0$ and EFC14146=1) as covariates. $\mathrm{Cl}$ : confidence interval, HR: hazard ratio, ITT: intention-to-treat, K-M: Kaplan-Meier, NE: not estimable, NSAID-ERD: non-steroidal anti-inflammatory drug-exacerbated respiratory disease, q2w: every 2 weeks, q4w: every 4 weeks, SCS: systemic corticosteroid.

the last SCS course. The mean number of SCS courses over the previous 2 years was 1.55. Further details on SCS use history are provided in Tables E2 and E3.

Sinonasal surgery and SCS use requirements during the study Dupilumab significantly reduced the number of patients who planned/underwent sinonasal surgery versus placebo during the treatment period by $82.6 \%$ (HR, $95 \%$ confidence interval $[\mathrm{Cl}]$ versus placebo 0.174 [0.066, 0.462]; $\mathrm{p}=0.0005)$ with $5(1.1 \%)$ patients receiving dupilumab requiring surgery compared with 22 (7.7\%) patients receiving placebo. Dupilumab reduced the sinonasal surgery rate irrespective of prior sinonasal surgery or prior SCS use within the last 2 years (Figure 2A). In patients with a history of prior sinonasal surgery, 4 (1.5\%) patients receiving dupilumab required sinonasal surgery during the study compared with 15 (8.0\%) patients receiving placebo.

Dupilumab also significantly reduced the need for SCS use versus placebo during the treatment period by $73.9 \%$ (HR, 95\% $\mathrm{Cl}$ versus placebo 0.261 [0.179, 0.379]; $\mathrm{p}<0.0001$ ) (Figure 2B) and reduced the number of SCS courses by $75.3 \%$ (relative risk [RR] [95\% Cl] 0.247 [0.167, 0.365]; nominal $\mathrm{p}<0.0001)$.

Fewer patients in the dupilumab group required SCS use 

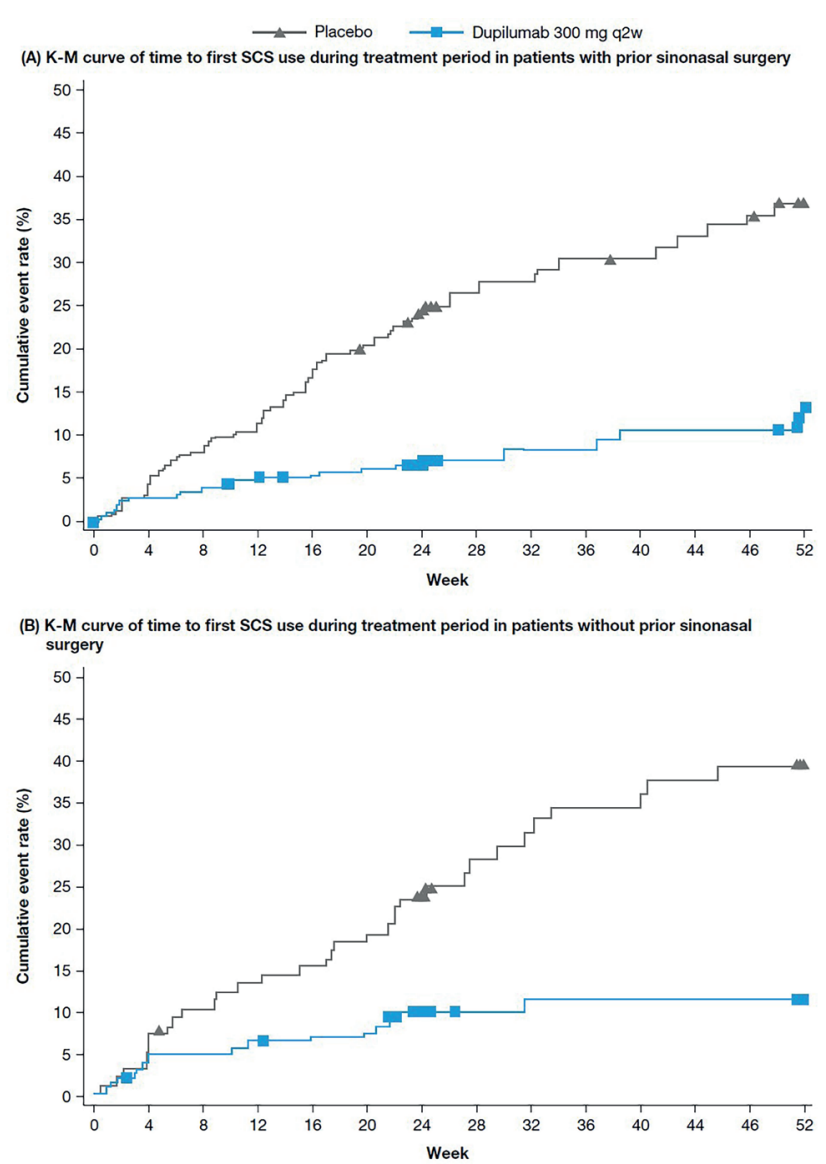

Figure 3. Need for SCS use during the treatment period in patients (A) with and (B) without prior sinonasal surgery - pooled ITT. ITT: intentionto-treat, K-M: Kaplan-Meier, q2w: every 2 weeks, SCS, systemic corticosteroid.

during the treatment period compared with those receiving placebo (41 [9.4\%] and 88 [30.8\%] patients, respectively). The mean (standard deviation [SD]) number of SCS courses during the treatment period was also lower in patients treated with dupilumab (0.21 [0.79] and 0.84 [1.88] for the dupilumab and placebo groups, respectively). The main reason for SCS use in both the dupilumab and placebo groups was for the relief of NP symptoms (15/41 [36.6\% of all patients who received SCSs] and $60 / 88$ [68.2\% of all patients who received SCSs] patients with dupilumab and placebo, respectively). Other reasons for SCS use in patients receiving dupilumab/placebo included asthma (8 [19. 5\%]/17 [19.3\%] patients), other respiratory disease (6 [14.6\%]/12 [13.6\%] patients), other ear, nose or throat disease (2 [4.9\%]/12 [13.6\%] patients), and any other reason (17 [41.5\%]/6 [6.8\%] patients). The annualised SCS dose, duration and number of SCS courses for dupilumab versus placebo during the treatment period were $60.5 \mathrm{mg}$ vs. $209.5 \mathrm{mg}, 2.6$ days vs. 7.2 days and 0.2 courses vs. 0.8 courses, respectively.

The reduction in SCS use during the treatment period in patients receiving dupilumab versus placebo was evident irrespec-
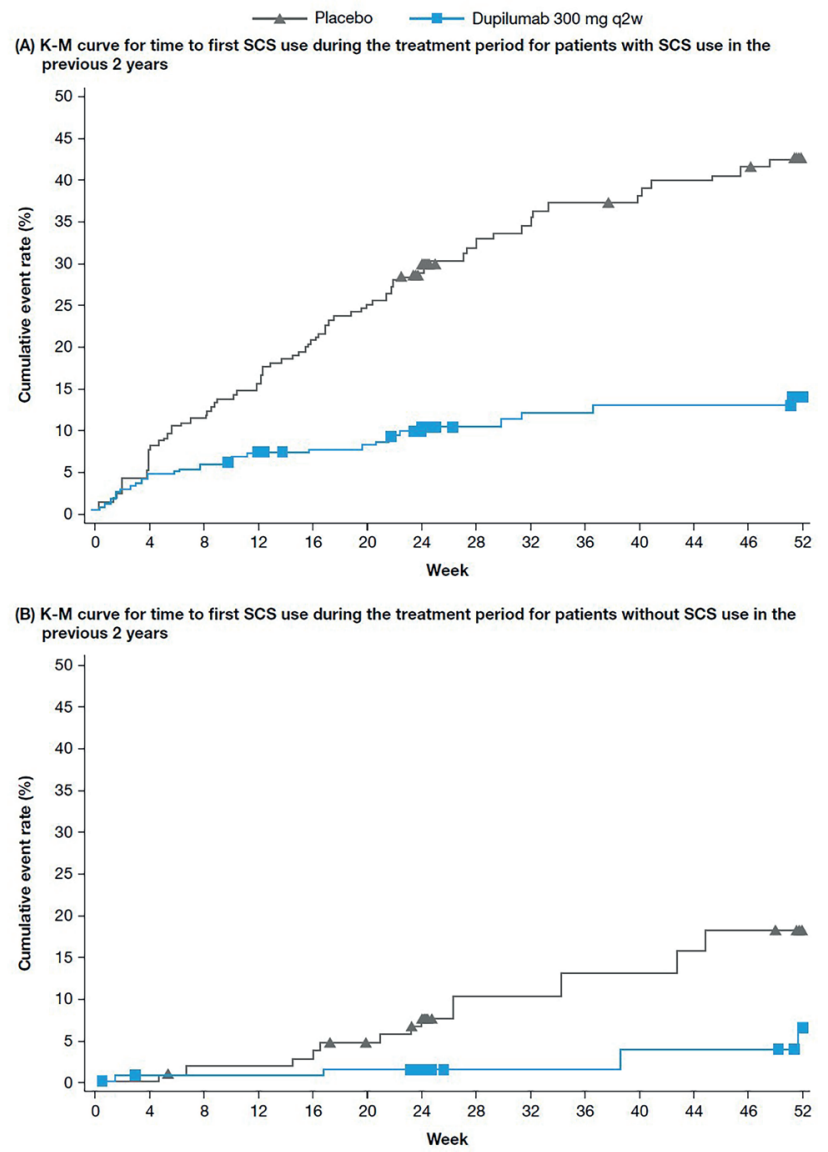

Figure 4. Need for SCS use during the treatment period in patients (A) with and (B) without SCS use - pooled ITT. ITT: intention-to-treat, K-M: Kaplan-Meier, q2w: every 2 weeks, SCS, systemic corticosteroid.

tive of a history of prior surgery (Figure $2 \mathrm{~B}$ / Figure 3/Table E4) or prior SCS use (Figure 2B/ Figure 4/Table E5). Similar reductions in SCS use were seen with dupilumab $300 \mathrm{mg}$ q2w and $300 \mathrm{mg}$ $\mathrm{q} 2 \mathrm{w}$-q4 $\mathrm{w}$ versus placebo in the SINUS-52 ITT population (Figure 2C) and in the pooled ITT population (Figure 2D).

Among the 129 patients with SCS use during the study, 17 (13.2\%) underwent sinonasal surgery during the study (placebo, $n=13 / 88$ [14.8\%]; dupilumab, $n=4 / 41$ [9.8\%]). Of the 27 patients who required sinonasal surgery during the study, 17 (63.0\%) also needed SCS during the study (placebo, $n=13 / 22$ [59.1\%]; dupilumab, $n=4 / 5$ [80.0\%]).

Results of sensitivity analyses, which included all data collected after SCS use, were consistent with the primary analysis (Table E6). The approaches used (WOCF/Ml; mixed effect model with repeat measures; and 'as-observed' analyses including data after SCS use) were highly significant in favour of dupilumab (all $p<0.0001$ ) supporting the efficacy of dupilumab over current standard of care.

Sinonasal outcomes in subgroups with/without SCS use and 
(A) NPS

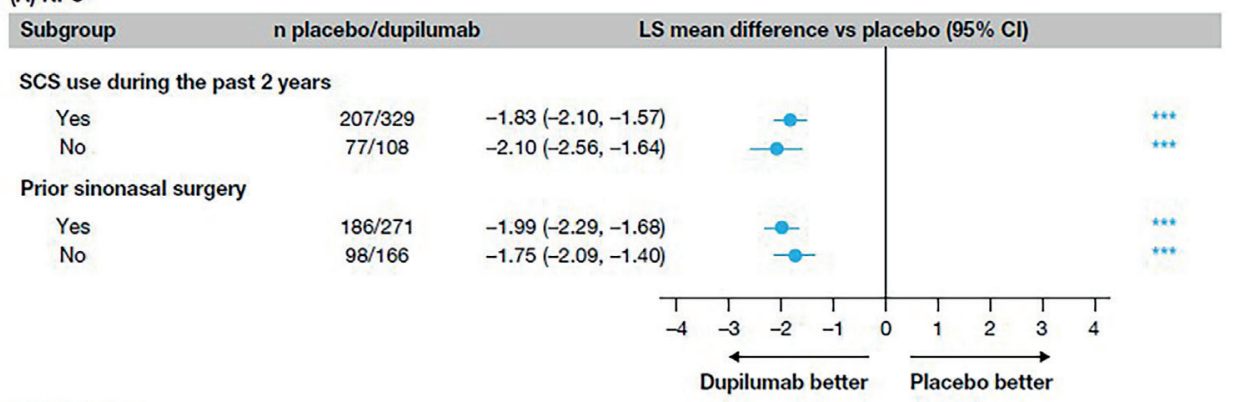

(B) NC score

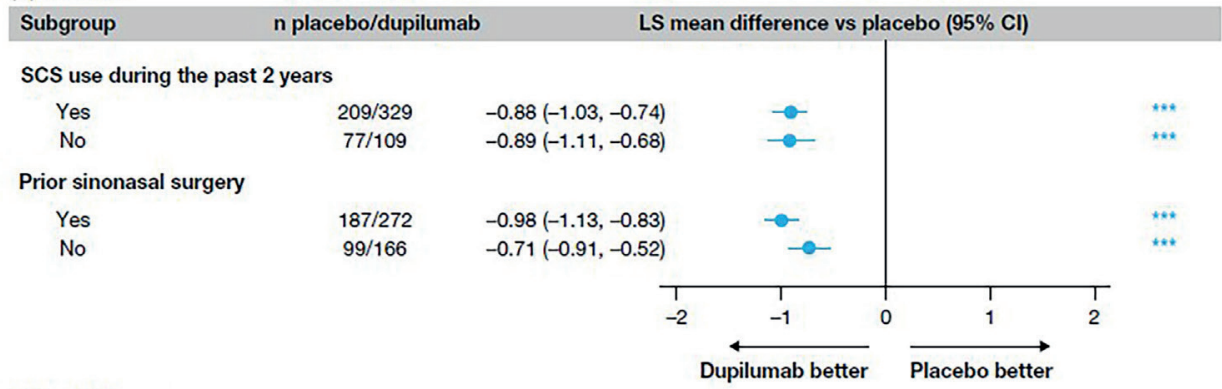

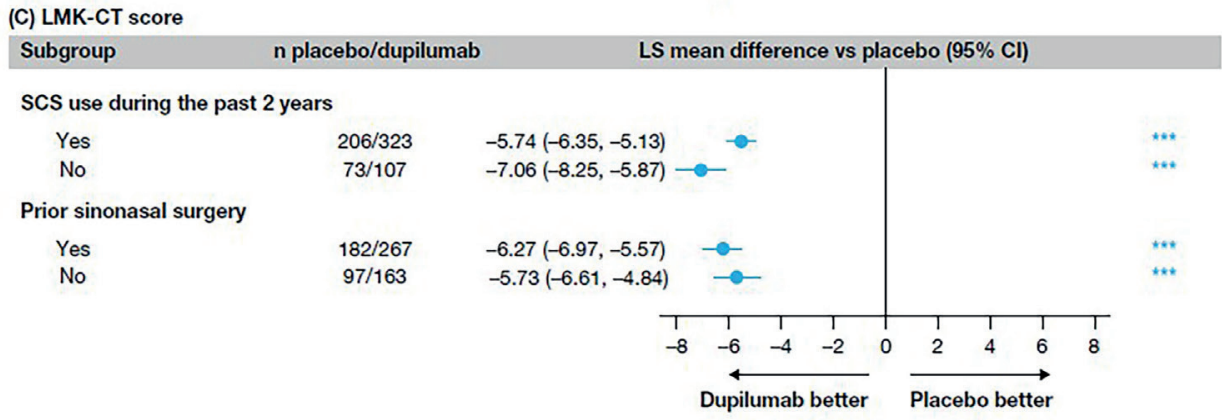

(D) SNOT-22 score

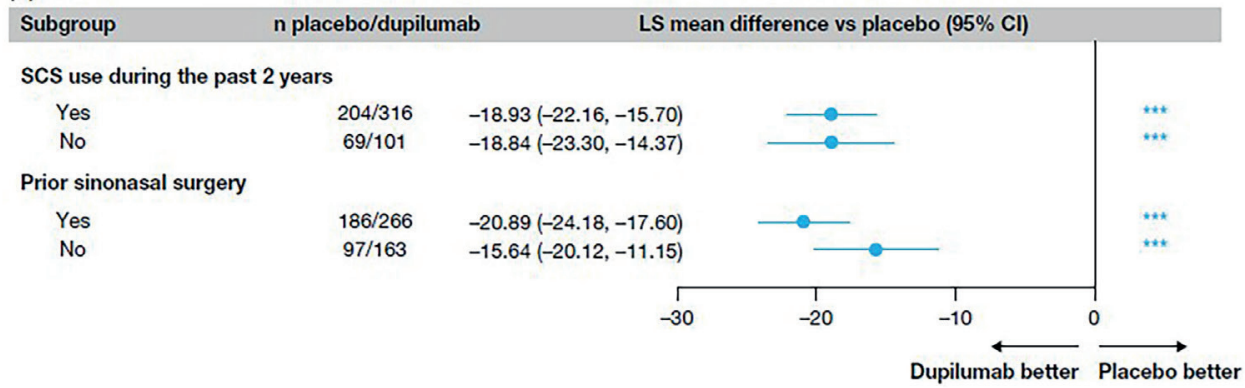

(E) UPSIT score

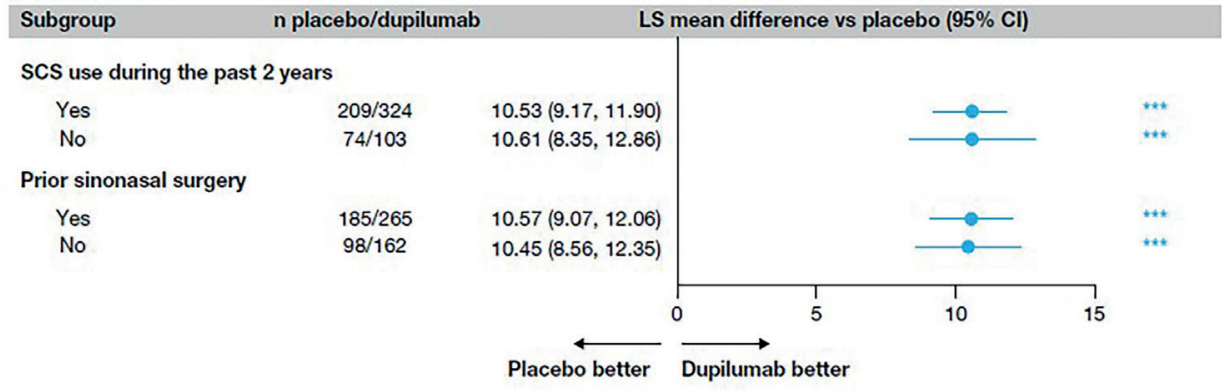

Figure 5. Effect of dupilumab on (A) NPS, (B) NC score, (C) LMK-CT score, (D) SNOT-22 score and (E) UPSIT score at Week 24 in patients with/without SCS use, and with/without prior sinonasal surgery. ${ }^{*} \mathrm{p}<0.05,{ }^{* *} \mathrm{p}<0.01,{ }^{* * *} \mathrm{p}<0.0001$. Efficacy endpoints were prospectively defined, and multiplicity adjusted and analysed using a hybrid method of WOCF and MI. Cl: confidence interval, CT: computed tomography, ITT: intention-to-treat, LMK: LundMackay, LS: least squares, MI: multiple imputation, NC: nasal congestion, NPS: nasal polyp score, SNOT-22: 22-item Sino-Nasal Outcomes Test, SCS: systemic corticosteroids, UPSIT: University of Pennsylvania Smell Identification Test, WOCF: worst observation carried forward. 
with/without prior sinonasal surgery

At baseline, NPS, NC score and LMK-CT score were similar among patients regardless of history of SCS use in the previous 2 years or prior sinonasal surgery (Table 1). Dupilumab consistently improved NPS and NC and LMK-CT scores versus placebo in patients with/without prior SCS use, and with/without prior sinonasal surgery (Figure 5A-C). Significant improvements versus placebo were also observed for SNOT-22 and UPSIT scores (Figure 5D, E). A total of 379 (84.2\%)/172 (66.2\%) patients with/ without surgery were anosmic at baseline with an UPSIT score of $\leq 18$. This was reduced to $234(53.4 \%) / 95$ (37.3\%) patients at Week 24.

\section{Safety}

Dupilumab was generally well tolerated. Non-fatal serious AEs occurred in 16/282 patients (5.7\%) receiving placebo and 15/440 patients (3.4\%) receiving dupilumab. Common AEs (in $\geq 5 \%$ of patients) were nasopharyngitis, headache, worsening NP and asthma, epistaxis and injection-site erythema, all of which occurred with higher frequency in placebo-treated patients. An overview of treatment-emergent AEs can be found in Table E7.

\section{Discussion}

The patients enrolled in SINUS-24 and SINUS-52 represented a population of adults with severe CRSwNP, as reflected by baseline characteristics of large polyps, severe symptoms, extensive bilateral sinus disease evidence on a CT scan, profoundly impaired sense of smell and substandard HRQoL. Their disease was inadequately controlled despite receiving the recommended standard of care, including INCS, SCSs and/or sinonasal surgery. Nearly three-quarters of patients (74\%) had received SCSs with an average of 1.55 courses in the previous 2 years and almost two-thirds (63.4\%) of patients had a history of sinonasal surgery throughout their lifetime with a mean of approximately 2 previous surgeries. These patients with uncontrolled disease responded well to dupilumab, and, remarkably, the magnitude of treatment effect was similar in patients with previous SCS treatment and/or sinonasal surgery (indicating refractory disease) compared with those who had not received such treatments previously. This demonstrates that dupilumab treatment for CRSwNP leads to consistent and clinically meaningful improvements in sinonasal outcome measures irrespective of previous therapy or surgery. Sensitivity analyses (including data collected after rescue SCS use) were consistent with the primary analysis results and further support the superior efficacy of dupilumab over standard of care including topical and systemic corticosteroids. In addition, $84.2 \%$ of patients who had previous sinonasal surgery were anosmic at baseline, but this was reduced to $53.4 \%$ of patients at Week 24 following dupilumab treatment. The overall improvement in sense of smell (UPSIT score) at Week 24 in patients receiving dupilumab versus placebo was 10.57 .
CRSwNP is a chronic predominantly type 2 inflammatory disease mediated by the key cytokines IL-4, IL-13 and IL-5, with in nasal polyp infiltration by eosinophils, basophils and mast cells ${ }^{(21)}$. Standard of care therapeutic options for patients with CRSwNP are often inadequate to achieve sustained disease control, as they do not always address the underlying type 2 inflammation. The existing treatment paradigm of frequent courses of SCS use (up to 3 before surgery is recommended) and/or recurrent surgeries results in high morbidity and inadequately controlled symptoms. This highlights the need for a shift towards a more holistic approach to CRSwNP management. Furthermore, other type 2 diseases such as asthma and AERD or N-ERD that are frequent comorbidities in patients with CRSwNP may also benefit from such treatment. These patients tend to have more severe CRSwNP disease, characterised by high NP recurrence rates after surgery and, often, corticosteroid dependence ${ }^{(4,22)}$. Similarly, patients with uncontrolled asthma who also have NP could benefit from treatment with dupilumab.

The SINUS studies were designed to evaluate the treatment effects of dupilumab in 'real-world' clinical settings and permitted the use of SCSs and surgery at the discretion of the treating investigators. The results showed a substantial steroid sparing effect of dupilumab with almost $74 \%$ reduction, relative to placebo (who received daily INCS), in the number of patients requiring SCS rescue use. The adjusted annualised total number of SCS courses was reduced by $\sim 75 \%$. Dupilumab also reduced the sinonasal surgery rate by $82.6 \%$ in the overall population. In addition, dupilumab showed similar significant effects in NPS and NC and LMK-CT scores across all settings including in patients with prior surgery ${ }^{(20)}$.

Multiple studies have demonstrated the significant undesirable effects of SCS use. Even with intermittent oral corticosteroid use, it has been shown that patients are at increased risk for sepsis, thromboembolism, osteopenia and fractures ${ }^{(23-25)}$. There is also evidence to suggest that suppression of cell-mediated immunity by corticosteroids can lead to recurrent viral infections, pneumonia and atypical bacterial infections such as tuberculosis(10). Surgical treatment options are considered relatively safe but are not completely without risks and can be associated with minor (reported incidence of 1.1-20.8\%) and major (0-1.5\%) risks such as severe bleeding or infection, and orbital/cranial damage ${ }^{(26)}$, as well as heightened risk of nosocomial infections ${ }^{(27)}$. Evolving concerns about surgery now also include the safety of personnel from aerosols generated during surgery and nasal endoscopy ${ }^{(28)}$. Traditional concerns about risks of immune suppression are also heightened in the context of widespread infection.

Dupilumab, thus, has the potential to reduce the risks associated with frequent and chronic use of SCS and with surgical procedures while also significantly restoring sense of smell, one of the most troublesome and difficult to treat symptoms for patients with CRSWNP. The continued reduction over 52 
weeks with dupilumab in the need for SCS use and/or sinonasal surgery reported here, along with the improvement in CRSwNP symptoms, demonstrates the suitability of dupilumab as a long-term treatment option in patients with severe CRSwNP. In the 1-year treatment period of SINUS-52, dupilumab did not increase overall infection rates compared with placebo and was associated with lower rates of respiratory infections in patients with CRSwNP(29).

The anti-IL-5 treatment, mepolizumab, is currently under investigation for treatment of eosinophilic NP. In patients with persistent NP treated with mepolizumab, a reduction in the proportion of patients that met the criteria for surgery has been reported, without providing the rate of reduction in true surgery or SCS use (16 [30\%] of patients receiving mepolizumab versus 5 [10\%] patients receiving placebo no longer meeting the criteria; $\mathrm{p}=0.006)^{(30)}$. Two recent phase 3 studies with the anti-IgE biologic omalizumab were completed and showed some reduction in SCS use (62.5\% relative reduction) and surgery need (defined by patients achieving NPS $\leq 4$ and a change of $\geq 8.9$ in SNOT-22 score) without reaching statistical significance; however, a very limited number of patients received SCSs or needed sinonasal surgery in both the placebo and omalizumab arms (8 [6.2\%] and 3 [2.3\%] patients, respectively; $\mathrm{p}=0.16)^{(31,32)}$. The use of biologics may pose a significant economic burden on healthcare systems and requires careful selection of patients. On the other hand, high costs are also associated with surgical treatment and SCS use in patients with CRSwNP, particularly in those with comorbid asthma ${ }^{(33-35)}$. Additional healthcare costs linked to oral corticosteroid-induced AEs have also been documented in severe asthma patients ${ }^{(9)}$. Dupilumab has the potential to provide ongoing disease control in CRSWNP, reducing the need for SCS use and sinonasal surgeries (with associated reduction in healthcare resource use), whilst improving $\mathrm{HRQ}$ oL for patients through reduction of disease burden and improvement of symptoms. A potential limitation of this current dupilumab analysis is that the type of sinonasal surgery prior to enrolment was not specified for participation in the trial which may have had an impact on the characteristics of the study population at baseline. In addition to this, the criteria for the need for SCS use and surgery and the dose and duration of SCS use were decided by the treating physicians. While this has the advantage to reflect real-life use, it may have caused variability in results, as such decisions may vary depending on the experience and judgement of the individual physician.

Dupilumab treatment was generally well tolerated. Common AEs (in $\geq 5 \%$ of patients) in the pooled safety population were nasopharyngitis, headache, worsening NP and asthma, epistaxis and injection-site erythema, all of which occurred with higher frequency in placebo-treated patients.

\section{Conclusion}

The results presented here suggest that dupilumab, as a continuous treatment that targets the key and central drivers of type 2 inflammation in CRSwNP, has the potential to provide continuous disease control, reduce the need for SCS use and sinonasal surgeries, bring about effective improvements in $\mathrm{HRQ}$ oL and restore olfactory function.

\section{Acknowledgements}

The authors thank the patients and their families for their participation in the studies; their colleagues for their support; Nora Crikelair (Regeneron Pharmaceuticals, Inc.) and Dianne Barry and Nadia Daizadeh (Sanofi) for their contributions, and Jérôme Msihid (Sanofi) for statistical analyses. Writing/editorial support in the preparation of this manuscript was provided by Sinéad Holland, PhD, of Excerpta Medica, funded by Sanofi Genzyme and Regeneron Pharmaceuticals, Inc.

\section{Authorship contribution}

$M D, L P M, J M$ and CB contributed to the study concept or design, data acquisition, and data analysis or interpretation. NA, AK, SK and NMHG contributed to the study concept or design and data analysis or interpretation. GWC, PWH, PG, SEL, JKH, CH, WJF, RJ, SC, XM, MZ and MR contributed to data acquisition, and data analysis or interpretation. SF and MR contributed to data analysis or interpretation.

\section{Conflict of interest}

Desrosiers M: AstraZeneca, GlaxoSmithKline, Probionase Therapies, Sanofi - clinical trial funding; Regeneron Pharmaceuticals, Inc., Sanofi - advisory board member; Probionase Therapies - equity holder. Mannent LP, Mao X, Zhang M, Rice M, Khan AH, Patel N: Sanofi - employees, may hold stock and/or stock options in the company. Amin N, Kamat S, Graham NMH, Ruddy M: Regeneron Pharmaceuticals, Inc. - employees and shareholders. Canonica GW: ALK, AstraZeneca, Boehringer Ingelheim, GlaxoSmithKline, HAL Allergy, Menarini, Mundipharma, Novartis, Regeneron Pharmaceuticals, Inc., Sanofi, Stallergenes Greer, Uriach Group - speaker fees, advisory board member. Hellings PW: Regeneron Pharmaceuticals, Inc., Sanofi - advisory board member. Gevaert P: 3NT, Ablynx, ALK, Argenx, AstraZeneca, Novartis, Regeneron Pharmaceuticals, Inc., Roche, Sanofi, Stallergenes Greer - advisory board member and speaker fees. Mullol J: ALK, AstraZeneca, Genentech, GlaxoSmithKline, Menarini, Mitsubishi-Tanabe, MSD, Mylan-MEDA Pharma, Novartis, Regeneron Pharmaceuticals, Inc., Sanofi, UCB, Uriach Group - clinical trial funding, advisory board member, or speaker fees; MylanMEDA Pharma, Uriach Group - research grants. Lee SE: Allakos, AstraZeneca, Knopp Biosciences, Sanofi - clinical trial funding; Novartis, Regeneron Pharmaceuticals, Inc., Sanofi - advisory board member. Fujieda S: Kyowa Hakko Kirin, Sanofi - advisory 
board member; Kyorin Pharmaceuticals - speaker fees. Han JK: Sanofi - advisory board member. Hopkins C: GlaxoSmithKline, Optinose, Sanofi Genzyme, Smith and Nephew - advisory board member. Fokkens W: Biolnspire Technologies, GlaxoSmithKline, Meda Pharmaceuticals, Sanofi - research grants. Jankowski R: ALK, Laboratoire de la Mer, Regeneron Pharmaceuticals, Inc., Sanofi - advisory board member. Cho SH: Regeneron Pharmaceuticals, Inc., Sanofi - research grant. Bachert C: ALK, AstraZeneca,
GlaxoSmithKline, Mylan, Novartis, Sanofi, Stallergenes Greer advisory board member and speakers' fees.

\section{Funding}

This research was sponsored by Sanofi and Regeneron Pharmaceuticals Inc. ClinicalTrials.gov Identifiers: NCT02912468 (SINUS-24) and NCT02898454 (SINUS-52).

\section{References}

1. Fokkens WJ, Lund V, Bachert C, et al. EUFOREA consensus on biologics for CRSwNP with or without asthma. Allergy 2019; 74: 2312-2319.

2. Khan A, Huynh TMT, Vandeplas G, et al. The GALEN rhinosinusitis cohort: chronic rhinosinusitis with nasal polyps affects healthrelated quality of life. Rhinology 2019; 57 : 343-351.

3. Orlandi RR, Kingdom TT, Hwang PH, et al. International consensus statement on allergy and rhinology: rhinosinusitis. Int Forum Allergy Rhinol 2016; 6 Suppl 1: S22-S209.

4. Calus L, Van Bruaene N, Bosteels C, et al. Twelve-year follow-up study after endoscopic sinus surgery in patients with chronic rhinosinusitis with nasal polyposis. Clin Transl Allergy 2019; 9: 30.

5. DeConde AS, Mace JC, Levy JM, Rudmik L, Alt JA, Smith TL. Prevalence of polyp recurrence after endoscopic sinus surgery for chronic rhinosinusitis with nasal polyposis. Laryngoscope 2017; 127: 550-555.

6. Hopkins C, Slack R, Lund V, Brown P, Copley $L$, Browne J. Long-term outcomes from the English national comparative audit of surgery for nasal polyposis and chronic rhinosinusitis. Laryngoscope 2009; 119: 24592465

7. Bachert C, Zhang N, Hellings PW, Bousquet J. Endotype-driven care pathways in patients with chronic rhinosinusitis. Clin Rev Allergy Immunol 2018; 141: 1543-1551.

8. Tokunaga $T$, Sakashita M, Haruna $T$, et al. Novel scoring system and algorithm for classifying chronic rhinosinusitis: the JESREC Study. Allergy 2015; 70: 995-1003.

9. Canonica GW, Colombo GL, Bruno GM, et al. Shadow cost of oral corticosteroids-related adverse events: A pharmacoeconomic evaluation applied to real-life data from the Severe Asthma Network in Italy (SANI) registry. World Allergy Organ J 2019; 12: 100007.

10. Heffler E, Madeira LNG, Ferrando M, et al. Inhaled corticosteroids safety and adverse effects in patients with asthma. J Allergy Clin Immunol Pract 2018; 6: 776-781.

11. Sarnes E, Crofford L, Watson M, Dennis G, Kan $H$, Bass D. Incidence and US costs of corticosteroid-associated adverse events: a systematic literature review. Clin Ther 2011; 33: 1413-1432.

12. Manson SC, Brown RE, Cerulli A, Vidaurre CF.
The cumulative burden of oral corticosteroid side effects and the economic implications of steroid use. Respir Med 2009; 103: 975-994.

13. Macdonald LE, Karow M, Stevens S, et al Precise and in situ genetic humanization of $6 \mathrm{Mb}$ of mouse immunoglobulin genes. Proc Natl Acad Sci USA 2014; 111: 51475152

14. Murphy AJ, Macdonald LE, Stevens S, et al Mice with megabase humanization of their immunoglobulin genes generate antibodies as efficiently as normal mice. Proc Natl Acad Sci USA 2014; 111: 5153-5158.

15. Le Floc'h A, Allinne J, Nagashima K, et al. Dual blockade of IL-4 and IL-13 with dupilumab, an IL-4Ra antibody, is required to broadly inhibit type 2 inflammation. Allergy. 2020; 75: 1188-1204.

16. Matsunaga K, Katoh N, Fujieda S, Izuhara K Oishi K. Allergol Int 2020; 69: 187-196.

17. DUPIXENT ${ }^{\circledR}$ (dupilumab). Highlights of prescribing information. US Food and Drug Administration 2019. Available at: https:// www.accessdata.fda.gov/drugsatfda_docs/ label/2019/761055s014lbl.pdf Accessed April 10, 2020

18. DUPIXENT ${ }^{\circledR}$ (dupilumab). Summary of Product Characteristics. European Medicines Agency. Available at: https:// ec.europa.eu/health/documents/community-register/2019/20190801145601/ anx_145601_en.pdf Accessed April 10, 2020

19. DUPIXENT ${ }^{\oplus}$ (dupilumab). Japan PDMA Available at: https://www.pmda.go.jp/ PmdaSearch/iyakuDetail/ResultDataSetPD F/780069_4490405G1024_1_05. Accessed April 10, 2020

20. Bachert C, Han JK, Desrosiers M, et al. Efficacy and safety of dupilumab in patients with severe chronic rhinosinusitis with nasal polyps (LIBERTY NP SINUS-24 and LIBERTY NP SINUS-52): results from two multicentre, randomised, double-blind, placebo-controlled, parallel-group phase 3 trials. Lancet 2019; 394: 1638-1650.

21. Gandhi NA, Bennett BL, Graham NMH, Pirozzi G, Stahl N, Yancopoulos GD. Targeting key proximal drivers of type 2 inflammation in disease. Nat Rev Drug Discov 2016; 15: 35-50.

22. Mendelsohn D, Jeremic G, Wright $E$ Rotenberg B. Revision rates after endoscopic sinus surgery: A recurrence analysis. Ann
Otol Rhinol Laryngol 2011; 120: 162-166

23. Waljee AK, Rogers MA, Lin P, et al. Shortterm use of oral corticosteroids and related harms among adults in the United States: population-based cohort study. BMJ 2017; 357: j1415.

24. Van Zele T, Gevaert P, Holtappels G, et al. Oral steroids and doxycycline: two different approaches to treat nasal polyps. J Allergy Clin Immunol 2010; 125: 1069-1076.e4.

25. Hox V, Lourijsen E, Jordens A, et al. Benefits and harm of systemic steroids for short- and long-term use in rhinitis and rhinosinusitis: an EAACI position paper. Clin Transl Allergy 2020; 10: 1.

26. Dessouky O, Hopkins C. Surgical versus medical interventions in CRS and nasal polyps: comparative evidence between medical and surgical efficacy. Curr Allergy Asthma Rep 2015; 15: 66.

27. Khan HA, Baig FK, Mehboob R. Nosocomial infections: epidemiology, prevention, control and surveillance. Asian Pac J Trop Biomed 2017; 7: 78-82.

28. Workman AD, Welling DB, Carter BS, et al Endonasal instrumentation and aerosolization risk in the era of COVID-19: simulation, literature review, and proposed mitigation strategies. Int Forum Allergy Rhinol 2020; https://doi.org/10.1002/alr.22577.

29. Bachert C, Gevaert P, Lee SE, et al. Dupilumab is associated with lower rates of respiratory infections in patients with chronic rhinosinusitis with nasal polyps safety analysis from the SINUS-52 phase 3 trial. Paper presented at 39th Annual digital congress of the European Academy of Allergy and Clinical Immunology; June 6-10, 2020

30. Bachert C, Sousa AR, Lund VJ, et al. Reduced need for surgery in severe nasal polyposis with mepolizumab: randomized trial. Allergy Clin Immunol 2017; 140: 1024-1031.

31. Gevaert P, Bachert C, Corren J, et al. Omalizumab efficacy and safety in nasal polyposis: results from two parallel, doubleblind, placebo-controlled trials. Ann Allergy Asthma Immunol 2019; 123: S14-S17.

32. Gevaert P, Omachi TA, Corren J, et al. Efficacy and safety of omalizumab in nasal polyposis: two randomized phase III trials, J Allergy Clin Immunol 2020. doi: https://doi. org/10.1016/j.jaci.2020.05.032

33. Bhattacharyya $\mathrm{N}$, Villeneuve $\mathrm{S}$, Joish VN, et 
al. Cost burden and resource utilization in patients with chronic rhinosinusitis and nasal polyps. Laryngoscope 2019; 129: 1969-1975.

34. Rudmik L. Economics of chronic rhinosinusitis. Curr Allergy Asthma Rep 2017; 17: 20.

35. Heffler E, Blasi F, Latorre M, et al. The Severe Asthma Network in Italy: findings and perspectives. J Allergy Clin Immunol Pract 2019; 7: 1462-1468.
Martin Desrosiers, MD

Département Oto-rhino-laryngologie Centre de recherche du Centre hospitalier de I'Université de Montreal (CRCHUM)

1051 Sanguinet

ENT Clinic, Pavillon C, 9th Floor

Montréal

H2X 3E4, QC

Canada

Tel: +1-514 8908000 Ext. 13278

E-mail:

desrosiers_martin@hotmail.com 


\section{SUPPLEMENTARY DATA}

Table E1. Baseline characteristics for patients with/without prior SCS use or with/without prior sinonasal surgery by treatment group.

\begin{tabular}{|c|c|c|c|c|c|c|c|c|}
\hline \multirow[t]{2}{*}{ Characteristic } & \multicolumn{2}{|c|}{ Placebo $(n=286)$} & \multicolumn{2}{|c|}{$\begin{array}{l}\text { Dupilumab } 300 \mathrm{mg} \\
\text { q2w ( } \mathrm{n}=438)\end{array}$} & \multicolumn{2}{|c|}{ Placebo $(n=286)$} & \multicolumn{2}{|c|}{$\begin{array}{l}\text { Dupilumab } 300 \mathrm{mg} \\
\text { q2w (n=438) }\end{array}$} \\
\hline & $\begin{array}{l}\text { With SCS } \\
(n=209)\end{array}$ & $\begin{array}{l}\text { Without } \\
\text { SCS }(n=77)\end{array}$ & $\begin{array}{l}\text { With SCS } \\
(n=329)\end{array}$ & $\begin{array}{l}\text { With- } \\
\text { out SCS } \\
(n=109)\end{array}$ & $\begin{array}{c}\text { With } \\
\text { surgery } \\
(n=187)\end{array}$ & $\begin{array}{c}\text { Without } \\
\text { surgery } \\
(n=99)\end{array}$ & $\begin{array}{c}\text { With } \\
\text { surgery } \\
(n=272)\end{array}$ & $\begin{array}{l}\text { Without } \\
\text { surgery } \\
(n=166)\end{array}$ \\
\hline Age, mean (SD), y & $\begin{array}{c}50.66 \\
(12.87)\end{array}$ & $\begin{array}{c}52.97 \\
(12.92)\end{array}$ & $\begin{array}{c}50.87 \\
(12.88)\end{array}$ & $\begin{array}{c}53.28 \\
(12.37)\end{array}$ & $\begin{array}{c}50.97 \\
(13.16)\end{array}$ & $\begin{array}{c}51.88 \\
(12.46)\end{array}$ & $\begin{array}{c}51.66 \\
(12.23)\end{array}$ & $\begin{array}{c}51.15 \\
(13.68)\end{array}$ \\
\hline Male sex, n (\%) & $124(59.3)$ & $41(53.2)$ & $214(65.0)$ & $58(53.2)$ & $103(55.1)$ & $62(62.6)$ & $165(60.7)$ & $107(64.5)$ \\
\hline NP duration, mean (SD), y & $10.35(8.99)$ & $12.12(8.97)$ & 10.05 (9.49) & $14.32(9.78)$ & $13.75(9.16)$ & $5.37(5.54)$ & $14.51(9.93)$ & $5.63(6.30)$ \\
\hline $\begin{array}{l}\text { Bilateral endoscopic NPS, mean } \\
\text { (SD), } 0-8^{+}\end{array}$ & $5.95(1.24)$ & $5.82(1.30)$ & $6.05(1.27)$ & $5.87(1.17)$ & $5.74(1.27)$ & $6.24(1.18)$ & $5.94(1.26)$ & $6.10(1.22)$ \\
\hline $\begin{array}{l}\text { Nasal congestion (AM) score, } \\
\text { mean (SD), } 0-3^{+}\end{array}$ & $2.45(0.53)$ & $2.32(0.58)$ & $2.41(0.59)$ & $2.36(0.63)$ & $2.47(0.53)$ & $2.30(0.56)$ & $2.42(0.59)$ & $2.35(0.63)$ \\
\hline $\begin{array}{l}\text { SNOT-22 total score, mean (SD), } \\
0-110^{+}\end{array}$ & $\begin{array}{l}53.45 \\
(21.41)\end{array}$ & $\begin{array}{c}49.05 \\
(20.08)\end{array}$ & $\begin{array}{c}51.31 \\
(20.37)\end{array}$ & $\begin{array}{c}46.13 \\
(19.81)\end{array}$ & $\begin{array}{c}53.47 \\
(19.92)\end{array}$ & $\begin{array}{c}49.98 \\
(23.17)\end{array}$ & $\begin{array}{c}50.35 \\
(20.32)\end{array}$ & $\begin{array}{c}49.57 \\
(20.41)\end{array}$ \\
\hline $\begin{array}{l}\text { Smell test (UPSIT) score, mean } \\
\text { (SD), } 0-40^{+}\end{array}$ & $14.19(8.03)$ & $13.80(9.07)$ & $14.01(7.89)$ & $13.57(8.97)$ & $13.01(7.46)$ & $16.13(9.39)$ & $12.65(7.57)$ & $15.95(8.68)$ \\
\hline $\begin{array}{l}\text { Sense of smell loss (AM) score, } \\
\text { mean (SD), } 0-3^{+}\end{array}$ & $2.77(0.45)$ & $2.61(0.66)$ & $2.75(0.51)$ & $2.73(0.64)$ & $2.77(0.48)$ & $2.63(0.57)$ & $2.80(0.55)$ & $2.66(0.52)$ \\
\hline LMK-CT score, mean (SD), $0-24^{+}$ & $18.54(4.09)$ & $18.51(4.18)$ & $18.11(4.04)$ & $18.72(3.99)$ & $19.16(4.10)$ & $17.34(3.86)$ & $19.01(3.89)$ & $17.04(3.97)$ \\
\hline TSS, mean (SD), 0-9 & $7.27(1.35)$ & $6.91(1.47)$ & $7.18(1.45)$ & $7.04(1.46)$ & $7.36(1.29)$ & $6.83(1.51)$ & 7.25 (1.39) & $6.98(1.54)$ \\
\hline $\begin{array}{l}\text { Rhinosinusitis severity (VAS), } \\
\text { mean (SD), 0-10 cm scale }{ }^{\dagger}\end{array}$ & $8.08(2.12)$ & $7.65(2.18)$ & $7.82(2.06)$ & $7.82(1.91)$ & $8.10(2.00)$ & $7.73(2.37)$ & $7.92(2.00)$ & $7.65(2.06)$ \\
\hline $\begin{array}{l}\text { Blood eosinophils, mean (SD), } \\
\text { median, Giga/L }\end{array}$ & $\begin{array}{c}0.45(0.35) \\
0.37\end{array}$ & $\begin{array}{c}0.42(0.29) \\
0.34\end{array}$ & $\begin{array}{c}0.43(0.35) \\
0.35\end{array}$ & $\begin{array}{c}0.41(0.35) \\
0.31\end{array}$ & $\begin{array}{c}0.46(0.32) \\
0.39\end{array}$ & $\begin{array}{c}0.40(0.37) \\
0.31\end{array}$ & $\begin{array}{c}0.47(0.39) \\
0.37\end{array}$ & $\begin{array}{l}0.36(0.27), \\
0.26\end{array}$ \\
\hline $\begin{array}{l}\text { Total lgE, mean (SD), median, } \\
\mathrm{IU} / \mathrm{mL}\end{array}$ & $\begin{array}{c}232.19 \\
(267.58) \\
138.00\end{array}$ & $\begin{array}{c}206.55 \\
(268.51) \\
103.50\end{array}$ & $\begin{array}{c}249.01 \\
(368.71) \\
126.50\end{array}$ & $\begin{array}{c}179.26 \\
(267.86) \\
80.00\end{array}$ & $\begin{array}{c}202.29 \\
(241.54) \\
116.00\end{array}$ & $\begin{array}{c}269.36 \\
(307.90) \\
152.50\end{array}$ & $\begin{array}{c}236.13 \\
(369.79) \\
100.00\end{array}$ & $\begin{array}{c}224.50 \\
(308.34) \\
131.00\end{array}$ \\
\hline $\begin{array}{l}\text { Patients with comorbid asthma, } \\
\text { n (\%) }\end{array}$ & $130(62.2)$ & $40(51.9)$ & $194(59.0)$ & $64(58.7)$ & $121(64.7)$ & $49(49.5)$ & $183(67.3)$ & $75(45.2)$ \\
\hline $\begin{array}{l}\text { Patients with comorbid NSAID- } \\
\text { ERD, } n(\%)\end{array}$ & $64(30.6)$ & $18(23.4)$ & $84(25.5)$ & $38(34.9)$ & $65(34.8)$ & $17(17.2)$ & $94(34.6)$ & $28(16.9)$ \\
\hline $\begin{array}{l}\text { Patients with } \geq 1 \text { prior sinonasal } \\
\text { surgery, } \mathrm{n}(\%)\end{array}$ & $118(100)$ & $69(100)$ & $174(100)$ & $98(100)$ & $187(100)$ & 0 & $272(100)$ & 0 \\
\hline $\begin{array}{l}\text { Previous sinonasal surgeries, } \\
\text { mean (SD) }\end{array}$ & $2.02(1.48)$ & $1.86(1.41)$ & $1.94(1.59)$ & $1.99(1.72)$ & $1.96(1.45)$ & 0 & $1.96(1.64)$ & 0 \\
\hline $\begin{array}{l}\text { Time since most recent sinona- } \\
\text { sal surgery, mean (SD), y }\end{array}$ & $7.10(6.20)$ & $6.99(6.59)$ & $7.17(6.47)$ & $7.31(6.65)$ & $7.06(6.33)$ & NA & $7.22(6.52)$ & NA \\
\hline $\begin{array}{l}\text { Time since last course of SCS } \\
\text { use }^{\ddagger, \S} \text { mean (SD), d }\end{array}$ & $\begin{array}{c}220.24 \\
(184.29)\end{array}$ & NA & $\begin{array}{c}214.49 \\
(188.23)\end{array}$ & NA & $\begin{array}{c}256.24 \\
(204.22)\end{array}$ & $\begin{array}{c}168.10 \\
(136.40)\end{array}$ & $\begin{array}{c}190.17 \\
(160.08)\end{array}$ & $\begin{array}{l}247.09 \\
(217.05)\end{array}$ \\
\hline $\begin{array}{l}\text { Patients with SCS use in the } \\
\text { previous } 2 \mathrm{y}, \mathrm{n}(\%)\end{array}$ & $209(100)$ & 0 & $329(100)$ & 0 & $118(63.1)$ & $91(91.9)$ & $174(64.0)$ & $155(93.4)$ \\
\hline $\begin{array}{l}\text { Number of SCS courses in the } \\
\text { previous } 2 y \text {, mean (SD) }\end{array}$ & $1.47(0.90)$ & NA & $1.60(1.34)$ & NA & $1.57(1.03)$ & $1.35(0.71)$ & $1.77(1.60)$ & $1.41(0.92)$ \\
\hline
\end{tabular}

TSS is a composite severity score consisting of the sum of daily symptoms of NC, loss of smell, and anterior/posterior rhinorrhoea. MCID for SNOT-22 score is 8.9. ${ }^{+}$Higher mean scores indicate more severe disease, except for UPSIT score where lower mean scores indicate more severe disease. ${ }^{\ddagger}$ Data are based on the pooled population: all patients randomised to dupilumab $300 \mathrm{mg}$ either q2w or q2w-q4w. ${ }^{5}$ Number of patients with $\geq 1$ day of SCS use and complete end dates reported. AM: morning, CT: computed tomography, d: day, IgE: immunoglobulin E, LMK: Lund-Mackay, MCID: minimum clinically important difference, NC: nasal congestion, NP: nasal polyps, NPS: nasal polyp score, NSAID-ERD: non-steroidal anti-inflammatory drugexacerbated respiratory disease, q2w: every 2 weeks, q4w: every 4 weeks, SNOT-22: 22-item Sino-Nasal Outcomes Test, SCS: systemic corticosteroid, SD: standard deviation, TSS: total symptom score, UPSIT: University of Pennsylvania Smell Identification Test, VAS: visual analogue scale: y, year. 
Table E2. SINUS-24 and SINUS-52: History of SCS use at baseline, number of courses.

\begin{tabular}{|c|c|c|c|c|c|}
\hline & \multicolumn{2}{|c|}{ SINUS-24: ITT } & \multicolumn{3}{|c|}{ SINUS-52: ITT } \\
\hline & Placebo $(n=133)$ & $\begin{array}{l}\text { Dupilumab } 300 \text { mg } \\
\text { q2w (n=143) }\end{array}$ & Placebo $(n=153)$ & $\begin{array}{l}\text { Dupilumab } 300 \text { mg } \\
q 2 w-q 4 w(n=145)\end{array}$ & $\begin{array}{l}\text { Dupilumab } 300 \mathrm{mg} \\
\text { q2w }(n=150)\end{array}$ \\
\hline $\begin{array}{l}\text { Patients with SCS use in the } \\
\text { previous year }{ }^{+} \mathrm{n}(\%)\end{array}$ & $71(53.4)$ & $77(53.8)$ & $101(66.0)$ & $91(62.8)$ & $97(64.7)$ \\
\hline 1 course & $55(77.5)$ & $60(77.9)$ & $80(79.2)$ & $67(73.6)$ & $75(77.3)$ \\
\hline 2 courses & $12(16.9)$ & $11(14.3)$ & $17(16.8)$ & $13(14.3)$ & $13(13.4)$ \\
\hline 3 courses & $4(5.6)$ & $6(7.8)$ & $2(2.0)$ & $5(5.5)$ & $3(3.1)$ \\
\hline 4 courses & 0 & 0 & $1(1.0)$ & 0 & $4(4.1)$ \\
\hline$\geq 5$ courses & 0 & 0 & $1(1.0)$ & $6(6.6)$ & $2(2.1)$ \\
\hline \multicolumn{6}{|l|}{ SCS courses in the prior year } \\
\hline Mean (SD) & $1.28(0.57)$ & $1.30(0.61)$ & $1.28(0.65)$ & $1.58(1.32)$ & $1.41(0.94)$ \\
\hline Median & 1.00 & 1.00 & 1.00 & 1.00 & 1.00 \\
\hline
\end{tabular}

${ }^{\dagger} \mathrm{A}$ course of SCS is considered continuous if treatment is separated by less than 7 days. ITT: intention-to-treat, q2w: every 2 weeks, q4w: every 4 weeks, SCS: systemic corticosteroid, SD: standard deviation.

Table E3. SINUS-24 and SINUS-52: History of SCS use at baseline, no. of days.

\begin{tabular}{|c|c|c|c|c|c|}
\hline & \multicolumn{2}{|c|}{ SINUS-24: ITT } & \multicolumn{3}{|c|}{ SINUS-52: ITT } \\
\hline & Placebo $(n=133)$ & $\begin{array}{l}\text { Dupilumab } 300 \mathrm{mg} \\
\text { q2w ( }=143)\end{array}$ & Placebo $(n=153)$ & $\begin{array}{l}\text { Dupilumab } 300 \mathrm{mg} \\
\mathrm{q} 2 \mathrm{w}-\mathrm{q} 4 \mathrm{w}(\mathrm{n}=145)\end{array}$ & $\begin{array}{l}\text { Dupilumab } 300 \mathrm{mg} \\
\text { q2w }(n=150)\end{array}$ \\
\hline \multicolumn{6}{|c|}{$\begin{array}{l}\text { Days with SCS use during the } \\
\text { last year }\end{array}$} \\
\hline Number ${ }^{\dagger}(\%)$ & $43(32.3)$ & $52(36.4)$ & $63(41.2)$ & $45(31.0)$ & $55(36.7)$ \\
\hline Mean (SD) & $11.58(9.41)$ & $13.48(18.32)$ & $13.05(11.53)$ & $42.84(83.64)$ & $46.15(84.24)$ \\
\hline Median & 10.00 & 10.00 & 8.00 & 14.00 & 12.00 \\
\hline Number ${ }^{\ddagger}(\%)$ & $71(53.4)$ & $77(53.8)$ & $101(66.0)$ & $91(62.8)$ & $97(64.7)$ \\
\hline $0-7$ days & 17/71 (23.9) & 15/77 (19.5) & $26 / 101(25.7)$ & $11 / 91(12.1)$ & 13/97 (13.4) \\
\hline 8-14 days & $16 / 71(22.5)$ & $25 / 77(32.5)$ & 21/101 (20.8) & $12 / 91(13.2)$ & 19/97 (19.6) \\
\hline 15-21 days & $5 / 71(7.0)$ & $8 / 77(10.4)$ & $3 / 101(3.0)$ & 6/91 (6.6) & $9 / 97(9.3)$ \\
\hline $22-28$ days & $3 / 71(4.2)$ & $2 / 77(2.6)$ & $3 / 101(3.0)$ & 3/91 (3.3) & $1 / 97(1.0)$ \\
\hline 29-56 days & $2 / 71(2.8)$ & $1 / 77(1.3)$ & 10/101 (9.9) & $7 / 91(7.7)$ & $4 / 97(4.1)$ \\
\hline 57-84 days & $0 / 71$ & $0 / 77$ & $0 / 101$ & $0 / 91$ & $2 / 97(2.1)$ \\
\hline $85-112$ days & $0 / 71$ & $0 / 77$ & $0 / 101$ & $2 / 91(2.2)$ & $0 / 97$ \\
\hline$>112$ & 8/71 (11.3) & $6 / 77(7.8)$ & $5 / 101(5.0)$ & $11 / 91(12.1)$ & 13/97 (13.4) \\
\hline Undetermined duration & $20 / 71(28.2)$ & $20 / 77(26.0)$ & $33 / 101(32.7)$ & 39/91 (42.9) & $36 / 97(37.1)$ \\
\hline
\end{tabular}

${ }^{+}$Number of patients with $\geq 1$ day of SCS use and complete dates reported. ${ }^{\ddagger}$ Number of patients with $\geq 1$ day of SCS use. ITT: intention-to-treat, q2w: every 2 weeks, q4w: every 4 weeks, SCS: systemic corticosteroid, SD: standard deviation. 
Table E4. Proportion of patients with SCS use during treatment period in patients with/without prior sinonasal surgery - pooled ITT.

\begin{tabular}{|c|c|c|c|c|}
\hline & \multicolumn{2}{|c|}{ With prior sinonasal surgery } & \multicolumn{2}{|c|}{ Without prior sinonasal surgery } \\
\hline & $\begin{array}{l}\text { Placebo } \\
(n=187)\end{array}$ & $\begin{array}{l}\text { Dupilumab } 300 \text { mg q2w } \\
\qquad(n=272)\end{array}$ & $\begin{array}{c}\text { Placebo } \\
(n=99)\end{array}$ & $\begin{array}{l}\text { Dupilumab } 300 \mathrm{mg} \text { q2w } \\
\qquad(\mathrm{n}=166)\end{array}$ \\
\hline Patients with SCS, n (\%) & $55(29.4)$ & $24(8.8)$ & $33(33.3)$ & $17(10.2)$ \\
\hline \multicolumn{5}{|c|}{$\begin{array}{l}\text { Kaplan-Meier estimates for probability of } \\
\text { a patient with } \geq 1 \text { event }(95 \% \mathrm{Cl}) \text { up to }\end{array}$} \\
\hline 16 weeks & $\begin{array}{c}0.176 \\
(0.126,0.234)\end{array}$ & $\begin{array}{c}0.052 \\
(0.030,0.083)\end{array}$ & $\begin{array}{c}0.152 \\
(0.090,0.230)\end{array}$ & $\begin{array}{c}0.067 \\
(0.035,0.111)\end{array}$ \\
\hline 24 weeks & $\begin{array}{c}0.241 \\
(0.183,0.305)\end{array}$ & $\begin{array}{c}0.071 \\
(0.044,0.106)\end{array}$ & $\begin{array}{c}0.234 \\
(0.156,0.321)\end{array}$ & $\begin{array}{c}0.097 \\
(0.058,0.148)\end{array}$ \\
\hline 40 weeks & $\begin{array}{c}0.302 \\
(0.228,0.379)\end{array}$ & $\begin{array}{c}0.105 \\
(0.063,0.159)\end{array}$ & $\begin{array}{c}0.361 \\
(0.256,0.466)\end{array}$ & $\begin{array}{c}0.115 \\
(0.066,0.179)\end{array}$ \\
\hline 52 weeks & $\begin{array}{c}0.368 \\
(0.281,0.456)\end{array}$ & $\begin{array}{c}0.129 \\
(0.079,0.192)\end{array}$ & $\begin{array}{c}0.393 \\
(0.283,0.500)\end{array}$ & $\begin{array}{c}0.115 \\
(0.066,0.179)\end{array}$ \\
\hline HR, $95 \% \mathrm{Cl}$ vs. placebo ${ }^{\dagger}$ & & $\begin{array}{c}0.244 \\
(0.150,0.397)\end{array}$ & & $\begin{array}{c}0.293 \\
(0.162,0.529)\end{array}$ \\
\hline $\mathrm{P}$ value vs. placebo ${ }^{\dagger}$ & & $<0.0001$ & & $<0.0001$ \\
\hline
\end{tabular}

${ }^{+}$HR derived from Cox proportional hazard model with the event of first SCS as the response variable and treatment, asthma/NSAID-ERD status, prior surgery history, region (pooled country), and study indicator (EFC14280 $=0$ and EFC14146=1) as covariates. Cl: confidence interval, HR: hazard ratio, ITT: intention-to-treat, NSAID-ERD: non-steroidal anti-inflammatory drug-exacerbated respiratory disease, q2w: every 2 weeks, SCS: systemic corticosteroid.

Table E5. Proportion of patients with SCS use during treatment period - patients with/without SCS use.

\begin{tabular}{|c|c|c|c|c|}
\hline & \multicolumn{2}{|c|}{ With prior SCS use } & \multicolumn{2}{|c|}{ Without prior SCS use } \\
\hline & Placebo $(n=209)$ & $\begin{array}{l}\text { Dupilumab } 300 \text { mg q2w } \\
\qquad(n=329)\end{array}$ & Placebo $(n=77)$ & $\begin{array}{l}\text { Dupilumab } 300 \text { mg q2w } \\
\qquad(n=109)\end{array}$ \\
\hline Patients with SCS, n (\%) & $76(36.4)$ & $37(11.2)$ & $12(15.6)$ & $4(3.7)$ \\
\hline \multicolumn{5}{|c|}{$\begin{array}{l}\text { Kaplan-Meier estimates for probability of } \\
\text { a patient with } \geq 1 \text { event }(95 \% \mathrm{Cl}) \text { up to }\end{array}$} \\
\hline 16 weeks & $\begin{array}{c}0.206 \\
(0.154,0.263)\end{array}$ & $\begin{array}{c}0.073 \\
(0.048,0.104)\end{array}$ & $\begin{array}{c}0.066 \\
(0.024,0.136)\end{array}$ & $\begin{array}{c}0.009 \\
(0.001,0.046)\end{array}$ \\
\hline 24 weeks & $\begin{array}{c}0.287 \\
(0.227,0.349)\end{array}$ & $\begin{array}{c}0.101 \\
(0.071,0.137)\end{array}$ & $\begin{array}{c}0.106 \\
(0.050,0.188)\end{array}$ & $\begin{array}{c}0.019 \\
(0.004,0.059)\end{array}$ \\
\hline 40 weeks & $\begin{array}{c}0.379 \\
(0.306,0.452)\end{array}$ & $\begin{array}{c}0.127 \\
(0.088,0.174)\end{array}$ & $\begin{array}{c}0.181 \\
(0.082,0.311)\end{array}$ & $\begin{array}{c}0.054 \\
(0.010,0.157)\end{array}$ \\
\hline 52 weeks & $\begin{array}{c}0.423 \\
(0.344,0.499)\end{array}$ & $\begin{array}{c}0.136 \\
(0.094,0.186)\end{array}$ & $\begin{array}{c}0.255 \\
(0.126,0.407)\end{array}$ & $\begin{array}{c}0.092 \\
(0.023,0.220)\end{array}$ \\
\hline HR, 95\% Cl vs. placebo ${ }^{\dagger}$ & & $\begin{array}{c}0.269 \\
(0.181,0.401)\end{array}$ & & $\begin{array}{c}0.194 \\
(0.062,0.612)\end{array}$ \\
\hline $\mathrm{p}$ value vs. placebo ${ }^{\dagger}$ & & $<0.0001$ & & 0.0051 \\
\hline
\end{tabular}

${ }^{\dagger}$ HR derived from Cox proportional hazard model with the event of first SCS as the response variable and treatment, asthma/NSAID-ERD status, prior surgery history, region (pooled country), and study indicator (EFC14280 $=0$ and EFC14146=1) as covariates. Cl: confidence interval, HR: hazard ratio, NSAID-ERD: non-steroidal anti-inflammatory drug-exacerbated respiratory disease, q2w: every 2 weeks, SCS: systemic corticosteroid. 
Table E6. Sensitivity analysis of primary endpoints: 'as-observed' data including all data collected after SCS use.

\begin{tabular}{|c|c|c|c|c|c|c|}
\hline \multirow{2}{*}{$\begin{array}{l}\text { Primary endpoints } \\
\text { (LS mean change } \\
\text { [SE] from baseline } \\
\text { at } \\
\text { Week 24) }\end{array}$} & \multicolumn{3}{|c|}{ SINUS-24 } & \multicolumn{3}{|c|}{ SINUS-52 } \\
\hline & $\begin{array}{l}\text { Placebo } \\
(n=133)\end{array}$ & $\begin{array}{l}\text { Dupilumab } \\
\qquad(n=143)\end{array}$ & $\begin{array}{l}\text { LS mean difference } \\
\text { dupilumab vs. placebo } \\
(95 \% \mathrm{CI})\end{array}$ & $\begin{array}{l}\text { Placebo } \\
(n=153)\end{array}$ & $\begin{array}{l}\text { Dupilumab } \\
(n=295)\end{array}$ & $\begin{array}{l}\text { LS mean difference } \\
\text { dupilumab vs. placebo } \\
(95 \% \mathrm{CI})\end{array}$ \\
\hline \multicolumn{7}{|l|}{ Bilateral NPS } \\
\hline WOCF/MI & $0.17(0.15)$ & $-1.89(0.14)$ & $-2.06(-2.43,-1.69)^{* * *}$ & $0.10(0.14)$ & $-1.71(0.11)$ & $-1.80(-2.10,-1.51)^{* * *}$ \\
\hline $\mathrm{MMRM}^{+}$ & $0.11(0.16)$ & $-2.02(0.14)$ & $-2.13(-2.52,-1.73)^{* * *}$ & $0.06(0.15)$ & $-1.78(0.10)$ & $-1.83(-2.16,-1.51)^{* * *}$ \\
\hline $\begin{array}{l}\text { As-observed } \\
\text { analysis }\end{array}$ & $0.09(0.15)$ & $-1.90(0.14)$ & $-1.98(-2.35,-1.61)^{* * *}$ & $-0.05(0.14)$ & $-1.83(0.11)$ & $-1.77(-2.07,-1.47)^{* * *}$ \\
\hline \multicolumn{7}{|l|}{ NC } \\
\hline WOCF/MI & $-0.45(0.07)$ & $-1.34(0.07)$ & $-0.89(-1.07,-0.71) * * *$ & $-0.38(0.07)$ & $-1.25(0.06)$ & $-0.87(-1.03,-0.71)^{* * *}$ \\
\hline $\mathrm{MMRM}^{+}$ & $-0.53(0.07)$ & $-1.41(0.06)$ & $-0.88(-1.05,-0.70)^{* * *}$ & $-0.51(0.07)$ & $-1.34(0.05)$ & $-0.82(-0.99,-0.65)^{* * *}$ \\
\hline $\begin{array}{l}\text { As-observed } \\
\text { analysis }\end{array}$ & $-0.56(0.07)$ & $-1.38(0.07)$ & $-0.82(-1.00,-0.65)^{* * *}$ & $-0.48(0.07)$ & $-1.28(0.06)$ & $-0.80(-0.95,-0.64)^{* * *}$ \\
\hline \multicolumn{7}{|l|}{ LMK-CT score } \\
\hline WOCF/MI & $-0.74(0.37)$ & $-8.18(0.34)$ & $-7.44(-8.35,-6.53) * * *$ & $-0.09(0.31)$ & $-5.21(0.24)$ & $-5.13(-5.80,-4.46)^{* * *}$ \\
\hline $\mathrm{MMRM}^{+}$ & $-1.15(0.40)$ & $-8.72(0.34)$ & $-7.57(-8.53,-6.61)^{* * *}$ & $-0.33(0.35)$ & $-5.54(0.24)$ & $-5.21(-5.97,-4.45)^{* * *}$ \\
\hline $\begin{array}{l}\text { As-observed } \\
\text { analysis }\end{array}$ & $-1.09(0.37)$ & $-8.40(0.34)$ & $-7.32(-8.22,-6.41)^{* * *}$ & $-0.47(0.30)$ & $-5.55(0.23)$ & $-5.09(-5.75,-4.43)^{* * *}$ \\
\hline
\end{tabular}

*** $\mathrm{p}<0.0001 .{ }^{\dagger}$ For MMRM approaches, for patients who underwent surgery for NP or received SCSs for any reason, data collected post-surgery or post-SCS use was set to missing. Cl: confidence interval, CT: computed tomography, LS: least squares, LMK: Lund-Mackay, MMRM: mixed effect model with repeated measurements, NC: nasal congestion, NPS: nasal polyp score, SCS: systemic corticosteroid, SE: standard error, WOCF/MI: worst observation carried forward/multiple imputation.

Table E7. Overview of TEAEs: pooled analysis of SINUS-24 and SINUS-52.

\begin{tabular}{|c|c|c|}
\hline \multirow[t]{2}{*}{ Patients with TEAEt, n (\%) } & \multicolumn{2}{|c|}{ Randomised treatment } \\
\hline & Placebo $(n=282)$ & Dupilumab 300 mg q2w ( $=440)$ \\
\hline Any TEAE & $208(73.8)$ & $305(69.3)$ \\
\hline Any serious TEAE & $16(5.7)$ & $15(3.4)$ \\
\hline Any TEAE leading to death ${ }^{\dagger}$ & 0 & 0 \\
\hline $\begin{array}{l}\text { Any TEAE leading to permanent treatment } \\
\text { discontinuation }\end{array}$ & $15(5.3)$ & $11(2.5)$ \\
\hline \multicolumn{3}{|c|}{ TEAEs occurring in $\geq 5 \%$ of patients (MedDRA PT) } \\
\hline Nasopharyngitis & $41(14.5)$ & $55(12.5)$ \\
\hline Headache & $24(8.5)$ & $32(7.3)$ \\
\hline Epistaxis & $20(7.1)$ & $25(5.7)$ \\
\hline Nasal polyps & $33(11.7)$ & $12(2.7)$ \\
\hline Asthma & $20(7.1)$ & $7(1.6)$ \\
\hline Injection-site erythema & $22(7.8)$ & $28(6.4)$ \\
\hline
\end{tabular}

${ }^{\dagger}$ Defined as events occurring from the time of signed informed consent until the end of the study by MedDRA PT. MedDRA: Medical Dictionary of Regulatory Activities, PT: preferred term, q2w: every 2 weeks, TEAE: treatment-emergent adverse event. 